\title{
Four New Species of the Genus Hyattella (Dictyoceratida: Spongiidae) from Korea
}

\author{
Chung Ja Sim¹, Kyung Jin Lee,** \\ ${ }^{1}$ Department of Biological Sciences, Hannam University, Daejeon 300-811, Korea \\ ${ }^{2}$ Biological Resources Coordination Division, National Institute of Biological Resources, \\ Incheon 404-708, Korea
}

\begin{abstract}
Four new species of the genus Hyattella (Dictyoceratida: Spongiidae); H. sinchangensis n. sp., H. mara n. sp., $H$. chuja n. sp. and $H$. lendenfeldi n. sp., were collected from Jeollanam-do and Jeju-do, Korea. Hyattella sinchangensis n. sp., H. mara n. sp., H. chuja n. sp. and H. grobosa Lendenfeld, 1889 are very similar to each other in some characters. However, Hyattella sinchangensis n. sp. characterized by no special dermal lamella and no tertiary fibres, and more thin secondary fibres than H. globosa. Hyattella mara n. sp. is differs in having well developed dermal lamella, slightly fasciculated primary fibres, and thick tertiary fibres. Hyattella chuja n. sp. differs in surface characters with a slightly elevated part, skeleton with abundant spongine, and very complex meshes. Hyattella lendenfeldi $\mathrm{n}$. sp. is similar to H. tenella (Lendenfeld, 1889) in skeletal structure, thickness of primary and secondary fibres, but differs in growth form.
\end{abstract}

Keywords: Hyattella, Spongiidae, Dictyoceratida, new species, Korea

\section{INTRODUCTION}

The family Spongiidae includes six valid genera; Spongia, Hippospongia, Coscinoderma, Hyattella, Leiosella and Rhopaloeides. Among them, the genus Hyattella was erected by Von Lendenfeld (1888). This genus was characterized by unarmoured surface, lacunose sponge body, and cored primary fibres (Cook and Bergquist, 2001; Hooper and Van Soest, 2002). Von Lendenfeld (1889) reported 14 species of Hyattella from Australia, and this was reviewed by Bergquist (1980). Van Soest (1978) discussed Hyattella intestinalis from Curacao and other Caribbean Islands and considered two types, massive and branches. Wiedenmayer (1977) summarized Hyattella cavernosa with Hyrtios cavernosus. Many other authors reported one or two species of the genus Hyattella (Willson, 1902; Dendy, 1905; De Laubenfels, 1936, 1948, 1954). To date, 12 valid species of the genus Hyattella has been reported worldwide (The World Porifera Database, 2013). In the present study, we discovered this genus for the first time in Korean waters.

\section{MATERIALS AND METHODS}

The material examined in this study was collected from Sinchang and Mara Island, Jeju-do and Gageodo Island, Jeollanam-do, Korea by SCUBA diving, 25-30 $\mathrm{m}$ in depth, during the period 2001-2007. All specimens were fixed in $95 \%$ or absolute ethanol. Identification was made on the basis of external features of sponges, including growth form, and skeletal structure and thickness. This procedure followed the methods of Sim and Lee (2002). Sponges were examined under steromicroscope (Stemi SV 6; Carl Zeiss, Jena, Germany) and light-microscope (Axiocop II; Carl Zeiss). The voucher specimens examined in this study were deposited in the National Institute of Biological Resources (NIBR), Incheon, Korea.

\section{SYSTEMATIC ACCOUNTS}

Phylum Porifera Grant, 1836

Class Demospongiae Sollas, 1885 (c) This is an Open Access article distributed under the terms of the Creative Commons Attribution Non-Commercial License (http://creativecommons.org/ licenses/by-nc/3.0/) which permits unrestricted non-commercial use, distribution, and reproduction in any medium, provided the original work is properly cited.

pISSN 2234-6953 eISSN 2234-8190

\section{*To whom correspondence should be addressed \\ Tel: 82-32-590-7232, Fax: 82-32-590-7040}

E-mail: kjlee89@korea.kr 
Order Dictyoceratida Minehin, 1900

Family Spongiidae Gray, 1867

${ }^{1 *}$ Genus Hyattella Lendenfeld, 1888

\section{${ }^{2 *}$ Hyattella sinchangensis n. sp. (Fig. 1)}

Type specimen. Holotype (NIBRIV0000282410), Korea: Jeju-do, Jeju-si, Hankyung-myeon, Sinchang-ri, 19 Oct 2001, Lee KJ, by SCUBA diving, $5 \mathrm{~m}$ in depth, deposited in the NIBR.

Description. Massive sponge, size up to $8 \times 6 \times 2.5 \mathrm{~cm}$. Surface with many holes $2-5 \mathrm{~mm}$ in diameter, which lead into extensive vestibular space of sponge body. Surface mostly smooth, covered with thin translucent dermal membrane which easily separates from endosome. End of primary fibres project to surface. Colour, purplish beige in life and, to yellowish beige in alcohol. Texture, hard and compressible. Skeleton. Primary fibres near surface well developed, 30-80 $\mu \mathrm{m}$ in diameter. Primary fibres in choanosome, 50-100 $\mu \mathrm{m}$ in diameter, rare. Primary fibres slightly cored with small sand grain. Secondary fibres, $20-30 \mu \mathrm{m}$ in diameter, clear. Secondary fibres, connected to each other and make irregular polygonal reticulation. Reticulated meshes, 100-300 $\mu \mathrm{m}$ in diameter.

Etymology. This species is named after its type locality, Sinchang, Jeju-do, Korea.

Remarks. This species is closely related to Hyattella grobosa Lendenfeld, 1889 in growth form and thickness of the primary fibres, but differs in the dermal membrane and thickness of the secondary fibres. This new species lacks a special dermal lamella and has thinner secondary fibres than those of Hyattella globosa (40-100 $\mu \mathrm{m}$ in diameter).

\section{${ }^{3 *}$ Hyattella mara n. sp. (Fig. 2)}

Type specimen. Holotype (NIBRIV0000282411), Korea:
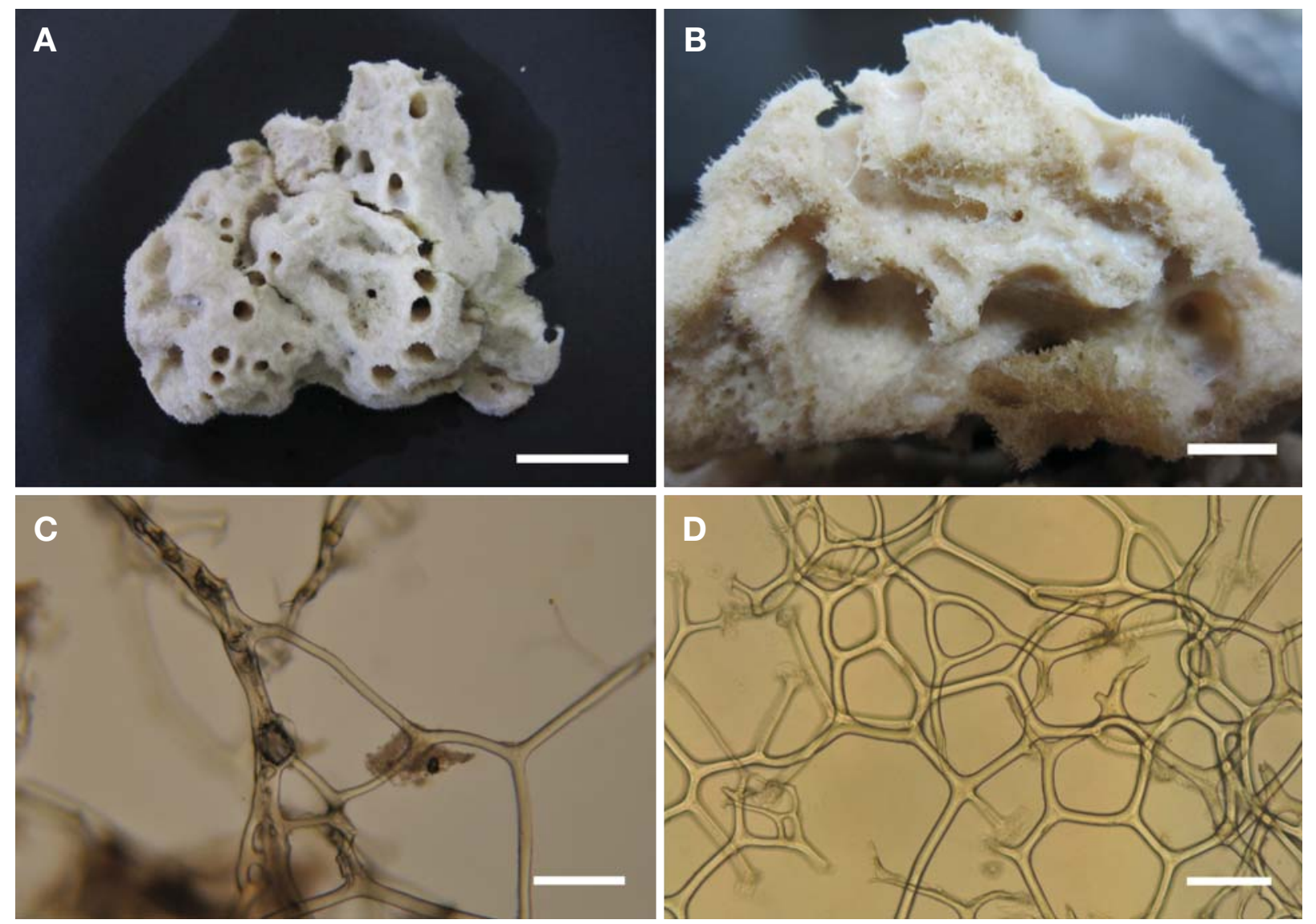

Fig. 1. Hyattella sinchangensis n. sp. A, Entire animal; B, Perpendicular section; C, Primary fibres; D, Secondary fibres. Scale bars: $A=2 \mathrm{~cm}, \mathrm{~B}=5 \mathrm{~mm}, \mathrm{C}, \mathrm{D}=200 \mu \mathrm{m}$.

Korean name: ${ }^{1 *}$ 히아텔라해면속, ${ }^{2 *}$ 신창히아텔라해면 (신칭), ${ }^{3 *}$ 마라히아텔라해면 (신칭) 

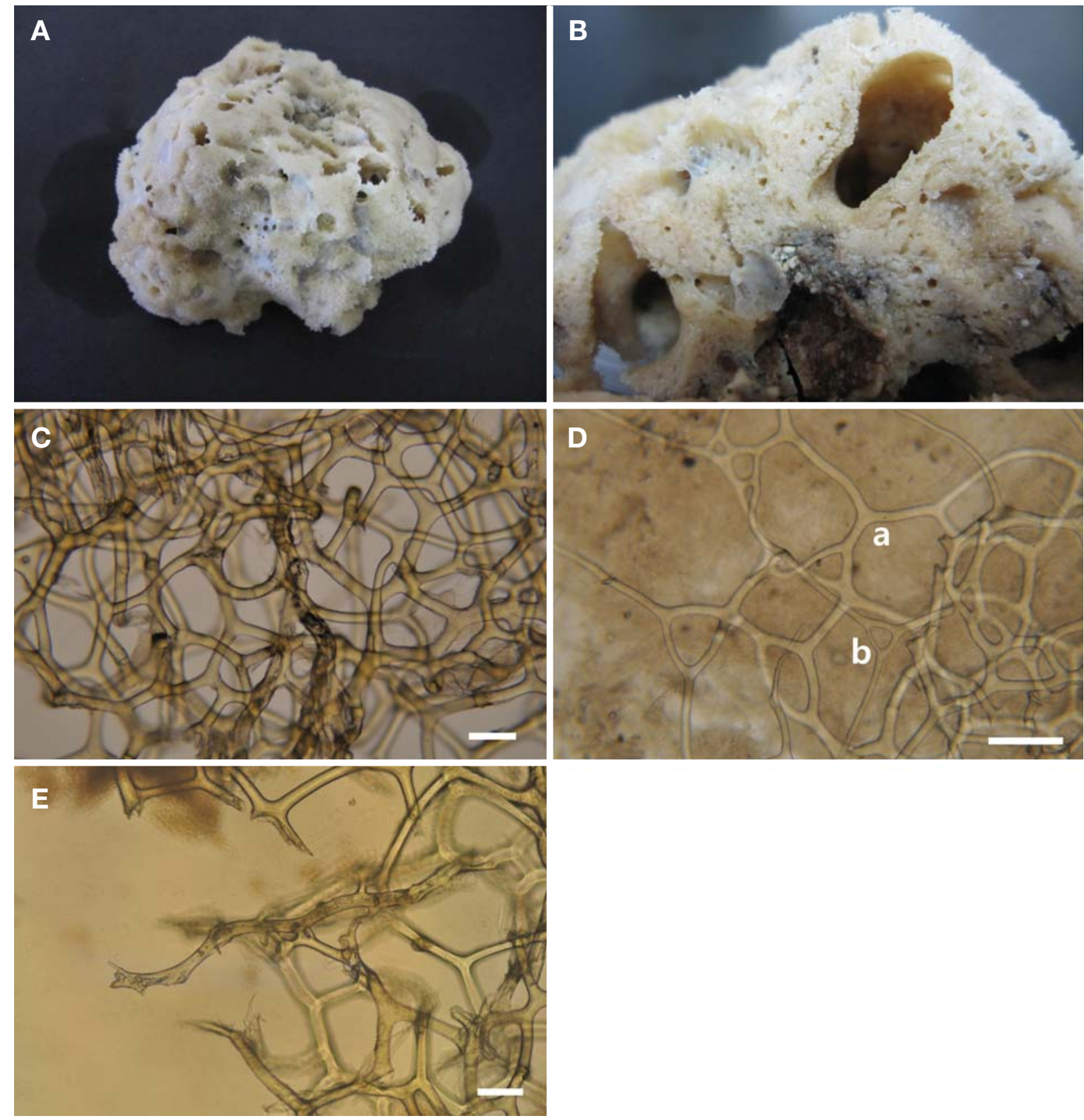

Fig. 2. Hyattella mara n. sp. A, Entire animal; B, Perpendicular section; C, Primary and secondary fibres network; $D$, Secondary and tertiary fibres ( $a$, secondary fibre; $b$, tertiary fibre); $E$, Primary fibres cored spicules. Scale bars: $A=2 \mathrm{~cm}, B=5 \mathrm{~mm}, C, D=200$ $\mu \mathrm{m}, \mathrm{E}=100 \mu \mathrm{m}$.

Jeju-do, Seogwipo-si, Daejung-eup, Marado Island, 22 Feb 2001, Lee KJ, by SCUBA $20 \mathrm{~m}$ in depth, deposited in the NIBR.

Description. Thickly encrusting, size up to $8.5 \times 7.5 \times 3 \mathrm{~cm}$. Surface rough with low conules, Special dermal lamella covered lacunae. Dermal membrane has hole-like oscules, 5-8 $\mu \mathrm{m}$ in diameter. Dermal membrane, difficult to separate from endosome. Colour beige in life. Texture firm and compressible. Skeleton consists of lightly fasciculated primary fibres $30-100 \mu \mathrm{m}$ in diameter, cored with sand and spicules. Rough primary fibres have protruded spicules near surface. Secondary fibres, no cored $30-40 \mu \mathrm{m}$ in diameter. Intricately connected secondary fibres make reticulated mesh of diverse size, Thin tertiary fibres, $20 \mu \mathrm{m}$ in diameter, derived from 
secondary fibres and uncored.

Etymology. This species is named after the type locality, Marado, Jejudo Island, Korea.

Remarks. This new species is closest to Hyattella sinchangensis and $H$. globosa Lendefeld, 1889 in growth, but differs in well-developed dermal lamella, slightly fasciculated primary fibres, and tertiary fibres. Most of all, this new species is easily distiguished from Hyattella sinchangensis and $H$. globosa by the existence of tertiary fibres. This new species is similar to $H$. chuja in having tertiary fibres, but they are thicker.

\section{${ }^{1 *}$ Hyattella chuja n. Sp. (Fig. 3)}

Type specimen. Holotype (NIBRIV0000282412), Korea: Jeju-do, Jeju-si, Chuja-myeon, Sinyang-ri, Jeolmyeongyeo, 1 Jul 2004, Lee KJ, by SCUBA diving, 25-35 $\mathrm{m}$ in depth, deposited in the NIBR.
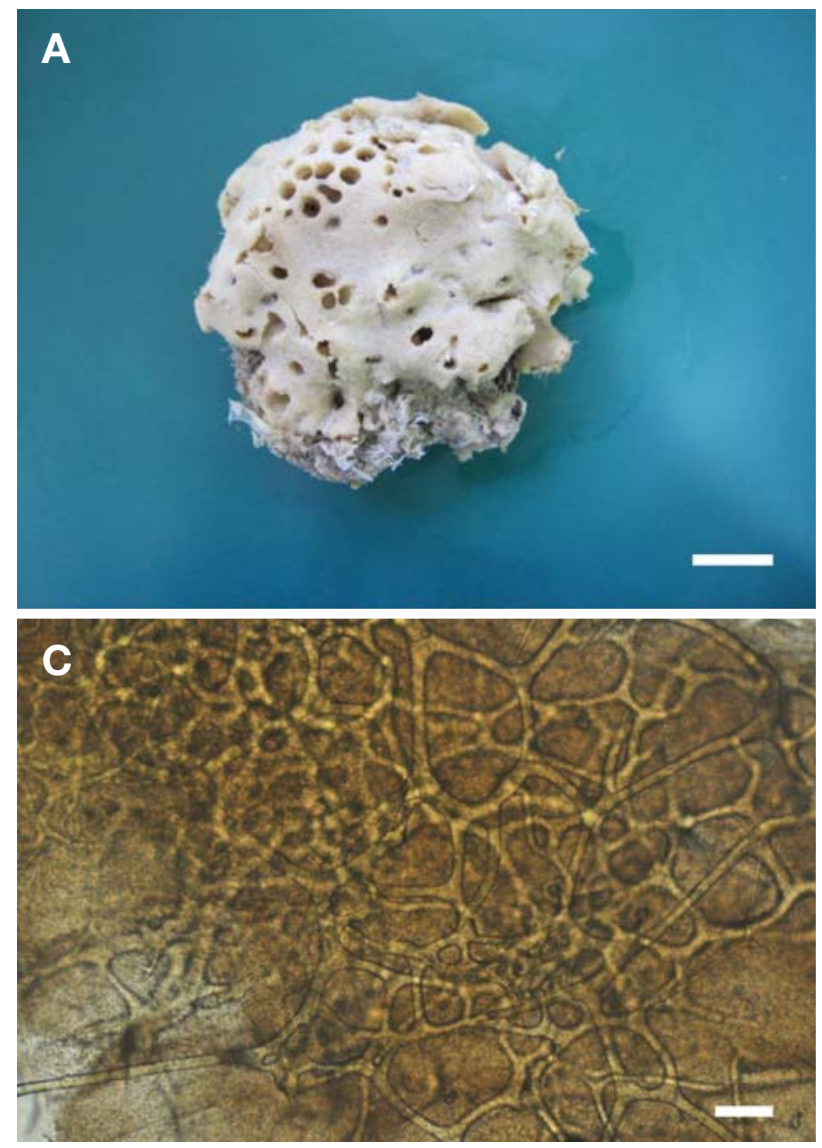

Description. Massive and thickly encrusting, size up to $10 \times$ $9 \times 2.5 \mathrm{~cm}$, on oyster shell (Crassostrea sp.). Many oscule like holes, 3-7 mm in diameter, open on surface. Some oscules open at the end of a slightly elevated part. Two or three large holes located together, or merge with each other. These multihole, irregularly scattered over sponge surface. Surface smooth with tiny protuberance. Texture, firm and compressible. Colour beige in life. Well-developed spongin forms strong skeletal structure. Fibres difficult to distinguish from well-developed matrix. Skeleton consists of irregularly arranged fibres. Primary fibres, $70-100 \mu \mathrm{m}$ in diameter, very lightly cored with sand and spicule. Some primary fibres not cored. Secondary fibres, $20-30 \mu \mathrm{m}$ in diameter, not cored. Meshes in mesohyl made by secondary fibres which form round polygonals, $40-200 \mu \mathrm{m}$ in diameter. Tertiary fibres, 6-10 $\mu \mathrm{m}$ in diameter, distributed under thin dermal membrane.

Etymology. This species is named after the type locality,
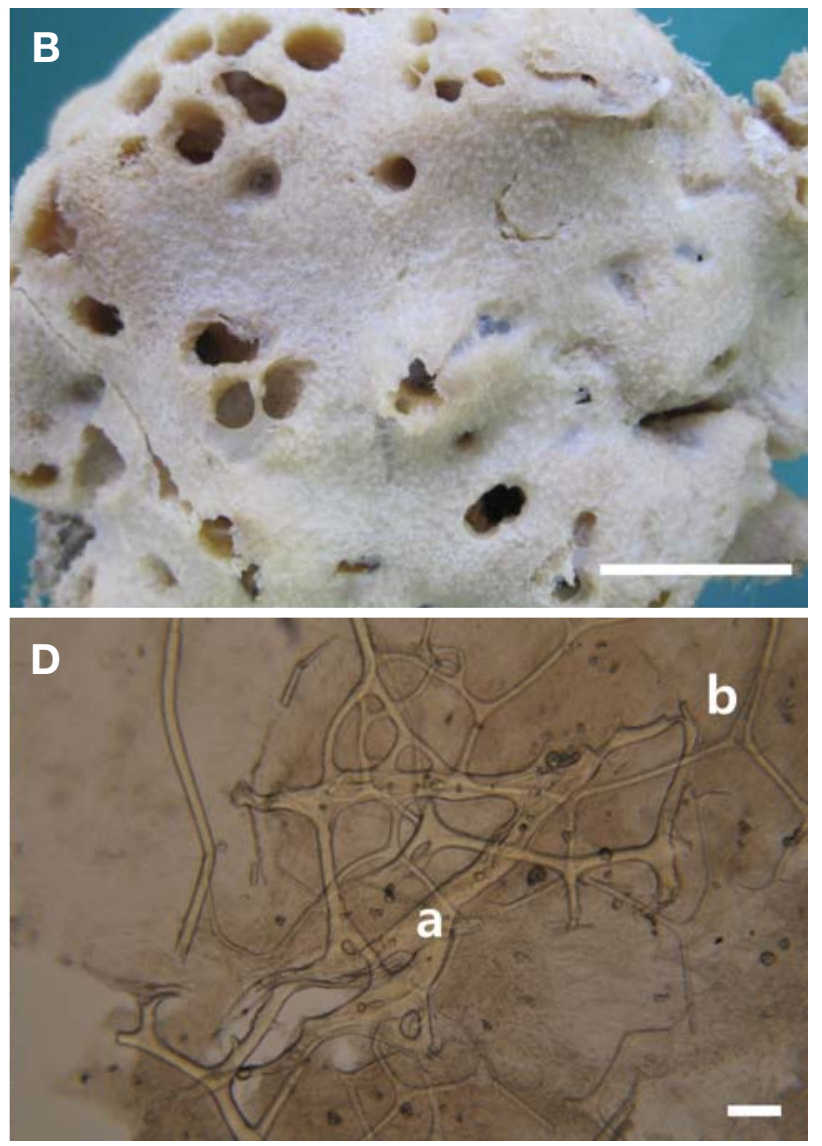

Fig. 3. Hyattella chuja n. sp. A, Entire animal; B, Closed surface; $C$, Secondary fibres; D, Primary and tertiary fibres (a, primary fibre; $b$, tertiary fibre). Scale bars: $A, B=2 \mathrm{~cm}, C=100 \mu \mathrm{m}, D=200 \mu \mathrm{m}$. 
Chujado, jejudo Island, Korea.

Remarks. Hyatella chuja n. sp. is closely related to $H$. sinchangensis, H. mara and H. globosa Lendenfeld, 1889 in growth form, but differs in the surface with a slightly elevated part, the skeleton with abundant spongin. This new species has a very complex mesh of secondary fibres compared with other species.

\section{${ }^{1 *}$ Hyattella lendenfeldi n. sp. (Fig. 4)}

Type specimen. Holotype (NIBRIV0000282413), Korea: Jeollanam-do, Shinan-gun, Heuksan-myeon, Gageodo Island, 20 Jul 2007, Kim HS, by SCUBA diving $15 \mathrm{~m}$ in depth, deposited in the NIBR.

Description. Massive sponge, size up to $11 \times 6 \times 7 \mathrm{~cm}$, with many tubercles. Numerous holes located at base of sponge body. Large holes, $5 \mathrm{~mm}$ in diameter, open at the end of tubes, $1-1.5 \mathrm{~cm}$ high. Each hole leads into internal cavities. Surface rough with many small conules, under $1 \mathrm{~mm}$ high, Primary fibres emerging out of sponge, connected with the conules. No special dermal membrane at surface. Colour purplish brown in life, more purple around large hole at top of tube. Texture soft and compressible. Matrix easily separated from fibres. Skeleton. Primary fibres, $40-70 \mu \mathrm{m}$ in diameter, cored with small amount of sand and broken spicules, and branched under sponge surface. Uncored secondary fibres, 20-50 $\mu \mathrm{m}$ in diameter, connected to each other, and make meshes $300-350 \mu \mathrm{m}$ in diameter between adjacent primary fibres.

Etymology. Hyattella lendelfeldi is named in honor of $\mathrm{R}$. Von Lendenfeld who erected genus Hyattella.

Remarks. This new species is similar to Hyatella tenella (Lendenfeld, 1889) in skeletal structure, thickness of primary and secondary fibres, but differs in growth form. This new species is not a branched form, but a tube with a large hole from a massive sponge.
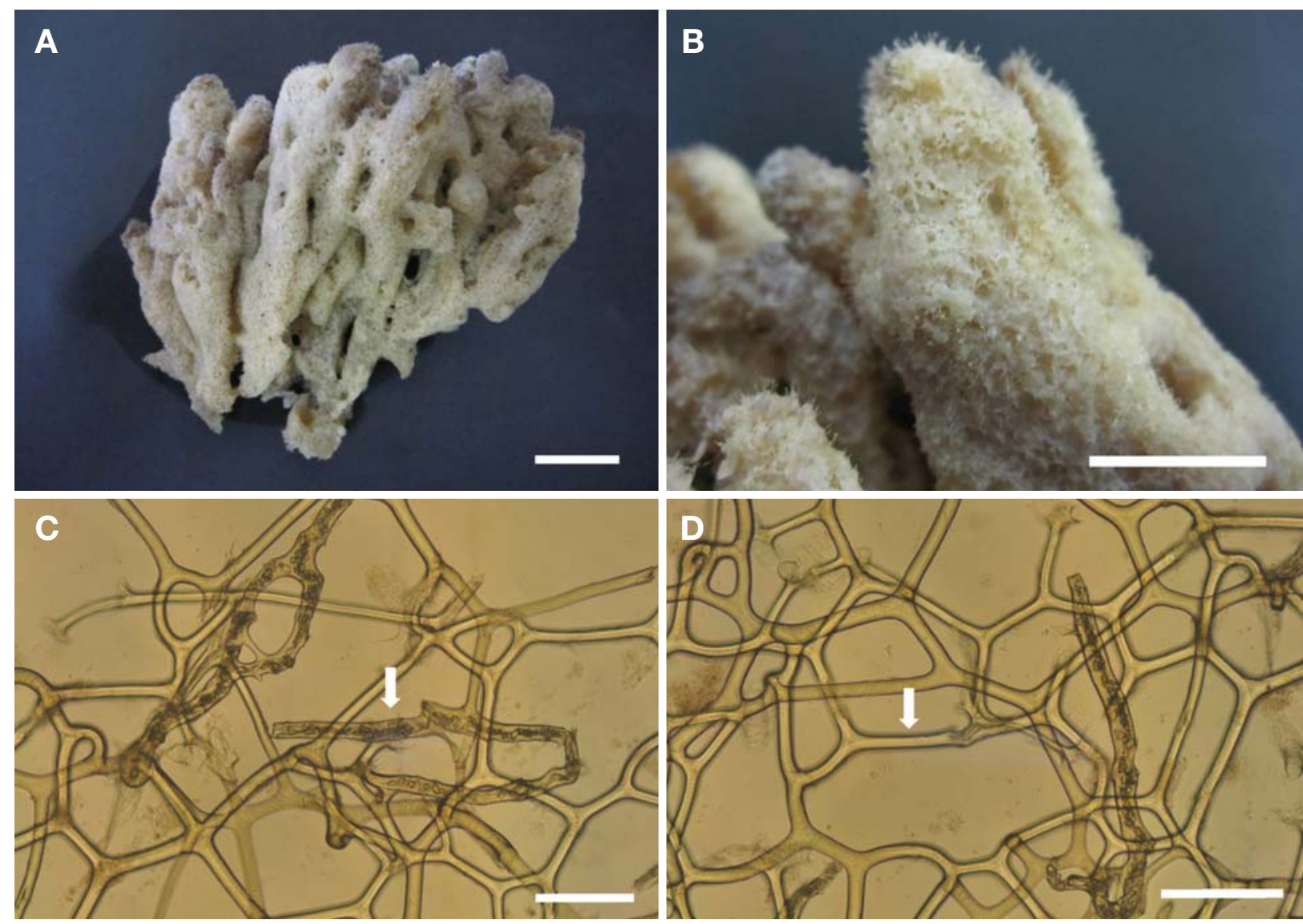

Fig. 4. Hyattella lendenfeldi n. sp. A, Entire animal; B, Surface; C, Primary fibres (arrow); D, Secondary fibres (arrow). Scale bars: $A=2 \mathrm{~cm}, \mathrm{~B}=1 \mathrm{~cm}, \mathrm{C}, \mathrm{D}=200 \mu \mathrm{m}$. 


\section{ACKNOWLEDGMENTS}

This research was supported by a grant from the National Institute of Biological Resources (NIBR) of Korea. We thank Dr. G. J. Bakus, Department of Biological science, University of Southern California for his advice and review of the manuscript.

\section{REFERENCES}

Bergquist PR, 1980. A revision of the supraspecific classification of the orders Dictyoceratida, Dendroceratida and Verongida (class Demospongiae). New Zealand Journal of Zoology, 7:443-503.

Cook SC, Bergquist PR, 2001. New species of Spongia (Porifera: Demospongiae: Dictyoceratida) from New Zealand, and a proposed subgeneric structure. New Zealand Journal of Marine and Freshwater Research 35:33-58.

De Laubenfels MW, 1936. A discussion of the sponge fauna of the Dry Tortugas in particular and the West Indies in general, with material for a revision of the families and orders of the Porifera. Carnegie Institute of Washington (Tortugas Laboratory Paper $\mathrm{N}^{\circ}$ 467), 30:1-225.

De Laubenfels MW, 1948. The order Keratosa of the phylum Porifera: a monographic study. Occasional Papers of the Allan Hancock Foundation, 3:1-217.

De Laubenfels MW, 1954. The sponges of the West-Central Pacific. Oregon State Monographs. Studies in Zoology 7:1306.

Dendy A, 1905. Report on the sponges collected by Professor
Herdman, at Ceylon, in 1902. pls I-XVI. In: Report to the Government of Ceylon on the Pearl Oyster Fisheries of the Gulf of Manaar. 3 (Supplement 18) (Ed., Herdman WA). Royal Society, London, pp. 57-246.

Hooper JNA, Van Soest RWM, 2002. Systema Porifera: a guide to the classification of sponges. Kluwer Academics/Pleum Publisher Press, New York, pp. 1-1101.

Sim CJ, Lee KJ, 2002. A new species in the family Irciniidae (Demospongiae: Dictyoceratida) from Korea. Korean Journal of Biological Sciences, 6:283-285.

Van Soest RWM, 1978. Marine sponges from Curaçao and other Caribbean localities. Part I. Keratosa. Studies on the Fauna of Curaçao and other Caribbean Islands, 56:1-94.

Von Lendenfeld R, 1888. Descriptive catalogue of the sponges in the Australian Museum, Sidney. Taylor \& Francis, London, pp. 1-260.

Von Lendenfeld R, 1889. A monograph of the horny sponges. Trübner and Co., London, pp. 1-936.

Wiedenmayer F, 1977. A monograph of the shallow-water sponges of the western Bahamas. Experientia Supplementum, 28:1-287.

Wilson HV, 1902 [1900]. The sponges collected in Porto Rico in 1899 by the U.S. Fish Commission Steamer Fish Hawk. Bulletin of the United States Fish Commission, 2:375-411.

The World Porifera Database, 2013. Vlaams Instituut Voor de Zee [Internet]. Oostende, Belgie, Accessed 14 Oct 2013, <http://www. marinespecies.org/porifera/>.

Received December 1, 2013 Revised January 13, 2014 Accepted January 15, 2014 